\title{
Précis of $A$ Virtue Epistemology (Oxford University Press, 2007)
}

\author{
Ernest Sosa
}

Published online: 30 January 2009

(C) Springer Science+Business Media B.V. 2009

My book draws a picture of human knowledge as a kind of successful cognitive performance. In order to know that $\mathrm{p}$ one must at a minimum attain an aim of one's belief that $\mathrm{p}$ : i.e., one must hit the mark of truth. A performance can attain its aim by sheer luck, however, in which case its success will not manifest the competence of the performer, either because the performance is not so much as competent, or else because, however competent it may or may not be, it is not its competence that accounts for its success. In order to be apt a performance must attain its basic aim, it must be a competent performance, and, further, its success must manifest its competence.

Animal knowledge is apt cognitive performance, apt belief. But there is a higher level of knowledge, reflective knowledge. Here the believer aptly notes, or implicitly presupposes, the aptness of his first-order belief.

The book details that picture of knowledge on its two levels. Framing the picture, the opening and closing chapters confront respective forms of skepticism. The first chapter confronts the dream skeptic, the last a kind of Pyrrhonian skeptic. The second chapter presents the basic account of knowledge, and the fifth develops it on its two levels. The two middle chapters take up as many issues recently prominent in epistemology, through the normativity of the apt belief. Thus, the third chapter takes up intuition as an epistemic source in line with our virtue epistemology, and the fourth offers a theory of epistemic normativity as a kind of performance normativity.

\footnotetext{
E. Sosa $(\square)$

Department of Philosophy, Rutgers, the State University of New Jersey, 26 Nichol Avenue, New Brunswick, NJ 08901-2881, USA

e-mail: ernsosa@rci.rutgers.edu
} 